\title{
Enunciação e forma linguística
}

\author{
Enunciation and linguistic form
}

\author{
Luiz Francisco Dias \\ Universidade Federal de Minas Gerais
}

\section{Resumo}

O texto analisa as abordagens da enunciação mais representativas nos estudos linguísticos do Brasil, com vistas a avaliar nesse âmbito o papel das formas linguísticas na constituição dos modelos teóricos. Em seguida, discute-se o conceito de forma linguística numa abordagem enunciativa voltada para a compreensão de lugares sintáticos da língua portuguesa. São abordados aspectos da qualificação da forma linguística e suas consequências para a identidade de lugares sintáticos que não se realizam com ocupação lexical. Nessa perspectiva, o conceito de acontecimento é fundamental, e é por meio dele que se discute a relação entre a forma linguística e a significação.

Palavras-chave

Enunciação e sintaxe, Acontecimento, Forma e sentido.

\section{Abstract}

The paper analyzes the most representative approaches of enunciation in language studies in Brazil, aiming at evaluating the role of linguistic forms in the constitution of theoretical models in this context. The concept of linguistic form from an enunciative approach is then discussed, with the objective of understanding syntactic places in Portuguese. Aspects of qualification of linguistic forms and their consequences in the identity of syntactic places, which do not occur with lexical occupation, are approached. In this perspective, the concept of occurrence is fundamental, and it 
is based on it that the relationship between linguistic form and meaning is discussed.

\section{Keywords}

Enunciation and syntax, Occurrence, Form and meaning. 


\section{Introdução}

A semântica da enunciação constitui-se de um conjunto de postulados teóricos que se agrupam em um campo que tem sido chamado de linguística da enunciação, dada a sua amplitude, e dada as variações da própria concepção de enunciação. Faz parte desse caráter variável de conceitos o papel das formas linguísticas no arcabouço teórico e metodológico dos modelos de análise enunciativa. Este texto procura apresentar os principais postulados teóricos sobre a enunciação que circulam no Brasil, bem como a postura que eles apresentam sobre o papel das formas da língua na constituição dos modelos de análise. A partir disso, apresentamos os fundamentos de uma linha de pesquisa que estamos desenvolvendo no sentido de definir um campo de trabalho voltado para a interface enunciado / sentença, com foco nos lugares sintáticos, concebidos como formas linguísticas qualificadas na relação entre o enunciável e o articulável.

\section{O campo de estudos da enunciação}

O termo enunciação foi utilizado nos estudos da linguagem em sentido amplo, como sinônimo de "coisa enunciada", como equivalente a "proposição" ou no sentido de "maneira de se enunciar". No final do século 18, segundo Delesalle (1986), o termo enunciação adquire sentido mais específico. Com efeito, Gabriel Girard, em 1747, defendia a tese segundo a qual o regime construtivo, responsável pela união gramatical das palavras, é sobreposto pelo regime enunciativo, responsável pela maneira como se opera a relação entre as palavras com vistas à formação da frase como uma unidade. Em termos atuais, o regime construtivo seria constituído segundo as forças da recção, que determinam a relação específica que um termo mantém com outro na ordem da contiguidade. Já o regime enunciativo determina a participação do termo na identidade do conjunto constituído enquanto frase. Nesse sentido, a frase como um todo contribui para a enunciação de cada palavra. ${ }^{1}$ 
No decorrer do século 19, surgem outros vieses de sentido para o termo enunciação, conforme aponta Delesalle (1986). No entanto, destacamos a perspectiva de Girard como visão precursora de um modo de conceber a enunciação desenvolvida por Benveniste, a partir de meados do século XX. Girard esboçou uma distinção que seria determinante na visão que Benveniste veio desenvolver sobre as formas e o uso da língua quando distingue o emprego das formas do emprego da lingua. Sobre o primeiro tipo, afirma Benveniste (1970, p. 81),

o emprego das formas constitui-se em um conjunto de regras fixando as condições sintáticas nas quais as formas podem ou devem normalmente aparecer, uma vez que elas pertencem a um paradigma que arrola as escolhas possíveis. Estas regras de emprego são articuladas a regras de formação indicadas antecipadamente, de maneira a estabelecer uma certa correlação entre as variações morfológicas e as latitudes combinatórias dos signos (acordo, seleção mútua, preposições e regimes dos nomes e dos verbos, lugar e ordem, etc.)

O emprego da língua, por sua vez, "implica uma outra maneira de ver as mesmas coisas, uma outra maneira de as descrever e de as interpretar" (BENVENISTE, 1970, p. 81). Nesse sentido, Benveniste vislumbra uma perspectiva de observação das formas linguísticas centrada, menos na articulação entre as regras de emprego e regras de formação, e mais na articulação entre as formas e as condições de funcionamento da língua; e nesse aspecto, a língua funciona por um ato de apropriação do locutor. Daí nasce uma afirmação clássica de Benveniste (1970, p. 82): “A enunciação é este colocar em funcionamento a língua por um ato individual de utilização". A condição específica da enunciação, segundo ele é "o ato mesmo de produzir um enunciado, e não o texto do enunciado, que é nosso objeto. (...) A relação do locutor com a língua determina os caracteres linguísticos da enunciação". Um determinado olhar sobre as formas da língua torna-se revelador do seu acionamento pelo locutor. Nessa direção, Benveniste destaca "um jogo de formas específicas, cuja função é de colocar o locutor em relação constante e necessária com sua enunciação" (BENVENISTE, 1970, p. 84). Os pronomes pessoais (ou "indivíduos linguísticos"), primordialmente, constituem-se nas formas básicas desse jogo, na perspectiva de Benveniste.

Portanto, a participação do sujeito na enunciação, em Benveniste, ocorre tendo em vista o ato de apropriação dessas formas individualizantes, a partir do qual a língua, instância de possibilidade, se realiza em instância de discurso. 
Dessa maneira, um olhar sobre as formas que permitem esse acionamento da língua como um todo, isto é, o emprego da língua, indicaria a existência de um verdadeiro aparelho de formas linguísticas (composto basicamente por pronomes, advérbios de tempo e lugar e tempos verbais), em função da enunciação. É só na enunciação que um pronome como "eu" adquire uma designação, na medida que um locutor se coloca na relação entre o aparelho formal, que é comum a todos os falantes, e sua enunciação, ao acionar a língua, constituindo-se discurso.

Benveniste concebe uma perspectiva com a qual se observa o funcionamento de determinadas categorias lexicais na enunciação, tendo em vista uma especificidade na sua designação. Algo diferente é desenvolvido por Ducrot, em uma abordagem da enunciação das mais conhecidas da atualidade.

Nos últimos 15 anos, Ducrot tem aprofundado a concepção não referencialista de Saussure, para quem o significado de um signo é o conjunto das relações que ele mantém com outros signos da língua. Tendo em vista que a noção de "relação com outros signos" mostra-se relativamente vaga, Ducrot, em parceria com Carel, consideram como semanticamente pertinentes as relações argumentativas, isto é, as relações entre um signo e outro que se ordenam com "portanto" (CAREL; DUCROT, 2005). Por exemplo, a significação da palavra "perto" consiste nos discursos evocados pela enunciação dessa palavra, cujos segmentos possam ser encabeçados por "portanto". Dessa maneira, a significação de uma frase como Meu hotel está perto da Faculdade será o conjunto de conclusões encabeçadas por "portanto" que podem ser extraídas dessa frase, por exemplo, a conclusão portanto é fácil de chegar lá (CAREL; DUCROT, 2005, 12). Nas palavras de Ducrot (2009, p. 23),

imaginemos a situação seguinte. $\mathrm{X}$ e $\mathrm{Y}$ devem ir juntos a determinado lugar L. Os dois sabem exatamente a que distância eles estão de L. X propõe a Y ir a pé a L. Y, se estiver de acordo, poderá responder sim, é perto. Se, ao contrário, ele quiser recusar, terá a possibilidade de dizer não, é longe. O que é que muda entre a qualificação perto e a qualificação longe? Não é a distância, que $\mathrm{X}$ e Y conhecem, tanto um quanto o outro. É somente a exploração argumentativa dessa distância. Dizendo perto, ela é apresentada como permitindo o passeio, dizendo longe, como pondo obstáculo a esse passeio. De modo que a escolha das conclusões sim ou não já está inscrita no próprio sentido dos argumentos é perto ou é longe. 
Assim, os encadeamentos autorizados por um signo, mediante o conector "portanto", constituem o seu sentido, e não as informações ou propriedades que ele sustenta.

A representação semântica única manifestada por um encadeamento recebe o nome de bloco semântico. Nos termos de Ducrot, "se meu discurso associa duas expressões bem distintas, depressa demais e infração, ele manifesta uma representação semântica única (na terminologia de Marion Carel, um bloco), que exprime a ideia única de velocidade proibida." (DUCROT, 2009, p. 22). Os encadeamentos que se mostram pertinentes na enunciação para "dirigir em alta velocidade" podem incluir "portanto pode sofrer uma infração" e "no entanto, não foi multado". Tanto o encadeamento com "portanto" quanto o encadeamento por "no entanto" operam na órbita do mesmo bloco semântico (velocidade proibida), produzindo a circunscrição de sentido do enunciado "dirigir em alta velocidade".

Trata-se, assim, de um modelo de análise da enunciação sustentado pela tese segundo a qual o sentido de um enunciado é puramente argumentativo. Segundo a Teoria dos Blocos Semânticos (TBS), que abriga esse modelo, "há encadeamentos argumentativos na própria significação das palavras e dos enunciados com os quais o discurso é feito. Nessas condições, toda palavra, tenha ela alcance persuasivo ou não, faz necessariamente alusão a argumentações." (DUCROT, 2009, p. 23). Na tese de Ducrot e Carel, procura-se nas discursividades aquilo que se constitui sintagmaticamente pelas articulações próprias da língua, isto é, aquilo que pode ser representado num esquema do tipo $\mathrm{x}$ CONECTOR y. Há um "já enunciado" que se instala no acontecimento da enunciação. Esse "já enunciado" constituiria a instância dos discursos evocados ou modificados na enunciação.

Efetivamente, o sentido de uma entidade linguística advém da evocação ou modificação de discursos, ou seja, o sentido é construído no encadeamento discursivo. Sob essa perspectiva, a tarefa de uma teoria da enunciação seria a de formular os limites do conjunto dos discursos doadores de sentido, e isso é proposto no modelo dos blocos semânticos na forma de sequências de duas proposições ligadas por um conector, constituindo-se dessa maneira encadeamentos argumentativos.

Nessa concepção, forma linguística não é algo definido em termos de categorias lexicais, mesmo porque, para Ducrot e Carel, a tese da significação como encadeamento argumentativo se aplica a qualquer classe do léxico. O conceito de forma se aplica à própria ordem do encadeamento, consubstanciada em x CONECTOR y. Em Ducrot e Carel, o direcionamento do que se diz é funda- 
mental para a significação. A conexão entre um signo dito $\mathbf{x}$ e um signo orientado para um dizer $\mathbf{y}$ arregimentando um conector consubstancia essa direção. A forma linguística se constitui numa qualificação que se produz entre a direção e o conector, tendo em vista a relação entre o dizer e o dito.

Ducrot e Benveniste são os teóricos que, majoritariamente, no Brasil, constituem-se em referência para os estudos da enunciação, entre as pesquisas que privilegiam o olhar sobre as formas da língua. Entre aquelas que desenvolvem questões da enunciação, mas não se atêm necessariamente às formas da língua, temos as constituídas em torno de conceitos de Bakhtin.

No âmbito do Grupo de Pesquisa Semântica do Acontecimento, ${ }^{2}$ diversos trabalhos empreendem análises com apoio em conceitos de Benveniste e Ducrot. No entanto, formulam-se direções de abordagem com características teóricas e metodológicas específicas. O trabalho de Guimarães (1987), voltado para as conjunções do português na perspectiva da teoria da enunciação, é um exemplo. Ele toma como base de análise a teoria da argumentação da língua, de Ducrot, e orienta as suas conclusões para a crítica ao conceito de intencionalidade, com vistas ao dimensionamento do conceito de efeito de sentido. Também de Guimarães (2002), temos o desenvolvimento específico dos conceitos de acontecimento e de lugares de enunciação, que passam pelos trabalhos de Ducrot, mas encontram ressonância em teses desenvolvidas no Brasil, relativas ao papel do histórico e do político nos estudos da linguagem. Além disso, o conceito de Domínio Semântico de Determinação (DSD) tem contribuído para a constituição de um viés metodológico bem definido na análise enunciativa (GUIMARÃES, 2007). Como ganho no conhecimento das formas da língua, que advém dos trabalhos desse Grupo, apontamos um olhar sobre as unidades lexicais concebido no espaço de enunciação da Língua Portuguesa no Brasil. A nossa participação no Grupo teve início com uma análise enunciativa das construções nominais, voltadas para o uso do termo Língua Brasileira, nas décadas de 1930 e 1940 (DIAS, 1996), e prossegue com a constituição de uma perspectiva enunciativa de abordagem dos lugares sintáticos do Português, cujos detalhes apresentaremos adiante, no presente artigo.

Ainda no âmbito dos estudos linguísticos brasileiros voltados para a enunciação, temos pesquisadores que exploram a relação entre enunciação e subjetividade, ou a "presença do homem na língua", conforme define Flores (1999, 2012). Nessa perspectiva, os aspectos relativos à forma linguística são desenvolvidos em Flores et alii (2008). Outro grupo de pesquisadores desenvolve o modelo da argumentação na língua, conforme os seus últimos desdobramentos, de acordo com Ducrot e Carel. Os trabalhos de Barbisan (2012) se situam nessa linha. Por 
sua vez, há trabalhos que se destacam pela abrangência na exploração de aspectos da língua portuguesa, do ponto de vista da enunciação. Nessa direção, em Fiorin (1996), encontramos uma análise exaustiva das categorias de espaço, tempo e pessoa no Português. Além disso, vale ressaltar, diversas pesquisas trabalham com aspectos da enunciação relativos ao discurso e ao sujeito, fundadas nas ideias de Bakhtin, conforme Brait (2001).

\section{Enunciação, forma linguística e regularidades sintáticas}

Em Dias (2002), formulamos alguns fundamentos de uma abordagem enunciativa dos fatos sintáticos, especificamente, o lugar do sujeito. Nesse texto, afirmamos que uma língua adquire sua identidade na relação entre a dimensão do enunciável e a dimensão do materialmente articulável, e é concebida como um sistema de regularidades (GUIMARÃES, 2007, p. 96) que regula essa relação. Aquilo que é enunciável só é apreendido como tal em caso de unidades que se articulam de maneira a construir formulações socialmente pertinentes. ${ }^{3}$ Por sua vez, a articulação de unidades só cumpre o seu papel de apreender o enunciável se ela se assenta em formas regulares, combinadas segundo padrões relativamente estáveis.

Nesse quadro, a enunciação é o acontecimento da constituição do enunciado. No acontecimento enunciativo, o articulável adquire formações legíveis, ${ }^{4}$ tendo em vista que o enunciável se faz pertinente na relação entre traços de memória (DIAS, 2012), advindos de enunciados outros, em outros tempos e lugares, e uma demanda atual, com vistas a significar o presente. Assim, as formas da língua são constitutivas da relação que se estabelece entre uma instância de presente do enunciar e uma instância de anterioridade (da memória).

Como vamos nos ater, neste trabalho, às articulações entre unidades formais de ordem sintática, é essencial discutir o conceito de materialidade qualificada, ou unidades formais qualificadas, para o estabelecimento de uma maior compreensão do que diz respeito à estruturação sintática. Para isso, vamos nos apoiar em Milner (1989), que desenvolveu o conceito de lugar sintático. ${ }^{5}$ Vejamos as seguintes construções, no sentido de discutir as repercussões desse conceito para a concepção de forma linguística:

(1) Pedro viu uma arma no chão.

(2) João colheu amoras no sítio do avô.

(3) No sítio do avô, João colheu amoras. 
O que estamos dizendo quando afirmamos que duas ou mais sentenças possuem a mesma sintaxe? Uma resposta que parece óbvia atualmente indica que estamos nos referindo à paridade dos lugares sintáticos. ${ }^{6}$ Com efeito, nas três sentenças acima, temos um verbo e os lugares de sujeito, complemento verbal e adjunto adverbial, segundo a terminologia tradicional. Nesse viés, teríamos a mesma sintaxe nas três sentenças, independentemente das unidades lexicais que estão ocupando esses lugares sintáticos. No entanto, esse raciocínio ignora as especificidades do papel que o verbo adquire frente às outras categorias lexicais na constituição de uma sentença. A par disso, Milner defende a tese segundo a qual a sintaxe se assenta na relação entre lugares sintáticos e não na relação entre unidades lexicais. Em (3), há uma mudança de localização do lugar de adjunto; no entanto, ela não produziu uma diferença na sintaxe. Sendo assim, consideramos o lugar sintático como "lugar qualificado", uma vez que ele se define, na Língua Portuguesa, com relativa independência em relação à localização na sentença.

O campo de pesquisa que estamos desenvolvendo guarda especificidades em relação aos modelos de pesquisa na área da semântica da enunciação apresentados no item anterior deste artigo. Um dos aspectos dessa especificidade reside na perspectiva de abordagem da forma linguística. Neste campo de investigação, a linha de trabalho é orientada pela busca de uma interface entre o enunciado e a sentença. Em Dias (2009), apresentamos detalhes relativos a essa interface. Um determinado olhar sobre as condições de ocorrência da sentença, isto é, as condições de ocupação dos lugares qualificados, produz o espaço de entremeio que buscamos para um conhecimento mais apurado do enunciado, a partir de uma visão dinâmica da sentença.

Vejamos um quadro com um pequeno conjunto de sentenças constituídas como laboratório. Trata-se de um campo de observação ${ }^{7}$ em que pares de sentenças sofrerão modificações em regime de colateralidade, com objetivos heurísticos. 


\section{QUADRO 1 \\ Campo de observação de lugares de sujeito e de objeto}

\begin{tabular}{|c|c|}
\hline LUGAR DO SUJEITO & LUGAR DO OBJETO \\
\hline (4Peder viu a arma, $\bullet$ apanhou, $\bullet$ levou e $\bullet$ guardou. & (4) Pedro viu garms apanhou $\mathbf{n}$, levou $\mathbf{m}$ e guardou $\mathbf{m}$ \\
\hline (4a) Pedro viu a arma. 0 menino apanhou e $\bullet$ guardou. & (4b) Pedro viu a arma. Apanhou o artefato guardoum \\
\hline 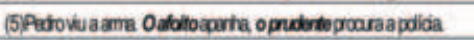 & (6) Pedo viu a ama. Apenhou orelogio, procurou a moeda. \\
\hline (7) Pedro viu uma arma. Aquele que sabe martemse prudente & 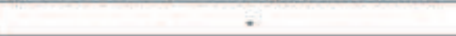 \\
\hline
\end{tabular}

Acreditamos que a leitura do quadro é reveladora a respeito da qualificação enunciativa, no que concerne aos lugares de sujeito e de objeto.

A ocorrência (4) nos indica que tanto o lugar de sujeito quanto o lugar de objeto, pertinentes aos verbos apanhar, levar e guardar podem ser afetados por uma força de retrospecção, isto é, quando não ocupados, esses lugares, representados pelo losango e pelo quadrado, podem receber uma determinação de retomada em um plano de anterioridade. Nessa ocorrência, "Pedro" e "a arma" encontram-se nesse plano de anterioridade. Por sua vez, as variações de ocorrência operadas em (4) nos mostram que o lugar do sujeito manifesta traços de uma especificidade em relação ao lugar de objeto. Em (4a), "Pedro" e "o menino", ou são correferentes, afetados pela força de retrospecção, ou são disjuntos na referência. Nesse caso, Pedro viu a arma, mas foi determinado menino quem a apanhou. Já em (4b), a força de retrospecção operou de forma a favorecer uma construção de sinonímia entre "arma" e "artefato". Se há uma correferencialidade nesse caso, ela é secundária.

Em (5), acreditamos que a força de retrospecção ainda atua, embora atenuada por um desdobramento prospectivo do caráter de Pedro. Em outros termos, sendo Pedro afoito, apanharia a arma; sendo prudente, chamaria a polícia.

Em (6), numa tentativa de formular algo colateral com (5), obtivemos um resultado diverso: a presença de brinquedo e moeda não são resultados, nem de uma força de retrospecção atenuada, e nem mesmo de prospecção, na forma de um desdobramento virtual da referência de "arma". Nesse caso, a ocupação do lugar do objeto é determinada pela construção da narrativa, que nesse caso deixa entrever movimentos dispersos do personagem Pedro.

Em (7), temos a atuação plena de uma força de prospecção. Nesse caso, "aquele que" representa um perfil referencial delineado, incluindo-se nele todos os que virtualmente saibam ou vierem a saber a respeito do perigo de apanhar 
uma arma que não seja sua, por exemplo. Também nesse caso, não pudemos formular algo colateral em relação ao lugar de objeto. Vejamos como seria uma construção dessa ordem:

(8) Aquele que procura acha

(9) Procura aquele que e achará (?)

Tudo indica que o lugar de objeto não é afetado pela força da prospecção.

Outro conjunto de ocorrências pode reforçar a nossa hipótese sobre a qualificação dos lugares de sujeito e objeto. cunhada.

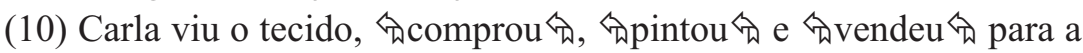

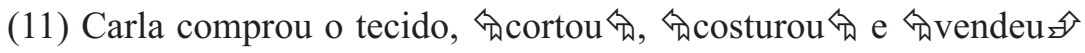
para a cunhada.

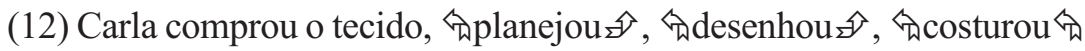
e 众vendeu㐱 para a cunhada.

Observemos em (10) que tanto o lugar do sujeito quanto o lugar do objeto estão afetados pela força da retrospecção, indicada pelo símbolo 匃. Em (11), por sua vez, o lugar do sujeito continua plenamente afetado pela retrospecção, garantindo a correferência. Já o lugar de objeto projetado pelo verbo vender é afetado por uma força de progressão, na medida que aponta para um objeto de memória (BERRENDONNER, 1990, 2002), que pode ser representado por roupa, vestido, ou algo desse contorno referencial. Em (12), essa força de progressão faz-se presente de maneira mais evidente, afetando três verbos do período.

Em todas as ocorrências, o lugar do sujeito mantém-se afetado somente pela força da retrospecção. Caso ocorra a ocupação do lugar do sujeito em (10), por exemplo, teremos outro período, relativo a outro acontecimento enunciativo, por exemplo:

(13) Carla viu o tecido, Tereza comprou命, Joana pintou角 e Vilma vendeu角 para a cunhada.

Por outro lado, caso eu queira ocupar o lugar de objeto do período (12), eu teria algo como (12'):

(12') Carla comprou o tecido, 勾planejou a roupa, 勿desenhou o molde, 勾costurou as partes e

Nesse caso, não se trata de outro período, mas do mesmo período, após a realização da força de progressão.

Assim, o efeito da força de progressão na ocupação do lugar de objeto, em casos de lugares não ocupados, é o de construção de objetos de memória apontados na relação com a temática desenvolvida. 
Vejamos o funcionamento da força de retrospecção em uma peça publicitária.

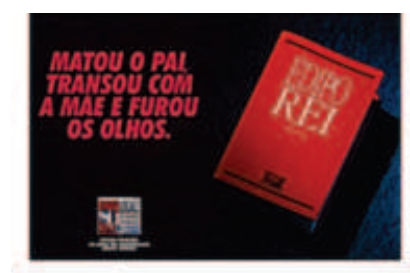

NOTICIAS POPULARES Um jomal tầo sensacionalista quanto Sófocles

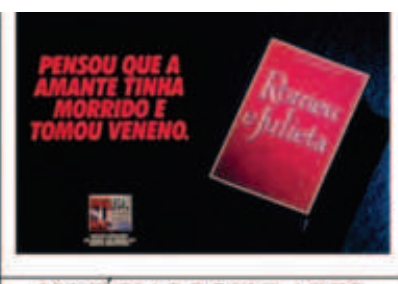

NOTÍCIAS POPULARES

Um jornal tâo mundo-cầ quanto Shakespeare

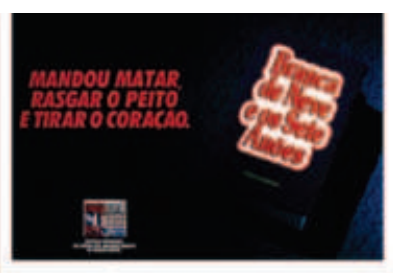

NOTICIAS POPULARES

Um jornal tão baixaria quanto Os Imalos Grimm

Fonte: Peça publicitária da Agência de Publicidade DM9, veiculada em 1992 e 1993 (citada em TEIXEIRA, 2005).

Essa propaganda se refere a jornal extinto em 2001, conhecido pelas matérias sensacionalistas. Veiculada em diversas revistas no País, o anunciante dirige-se ao leitor que teve acesso ao acervo da cultura escrita universal, possivelmente aquele que criticava o Notícias Populares pela baixaria. Destacamos nos quadros abaixo da peça publicitária aquilo que se encontra no texto da propaganda, mas de forma pouco legível. Observemos que as formas verbais "matou", "pensou" e "mandou" evocam referentes que não estão necessariamente explicitados no espaço do texto publicitário. A força de retrospecção que opera no lugar do sujeito não ocupado, participando da sua constituição como espaço enunciativamente qualificado, leva-nos ao plano de anterioridade no qual o referente deve ser identificado. No primeiro quadro, trata-se de Édipo; no segundo, de Romeu, cujo nome não se encontra na face visual da peça publicitária; e no terceiro, a madrasta, cujo nome também não aparece no texto.

Tal como observamos nas ocorrências de (4) a (12), a força de retrospeção que move a virtual ocupação do lugar do sujeito recebe uma injunção à definitude, motivada pela correferencialidade. Na peça, essa injunção à definitude é motivada pela identificação. Quando a força de retrospecção atua na ocupação virtual do lugar de objeto, não podemos rigorosamente falar em correferencialidade e nem em identidade, como demonstra (10):

cunhada.

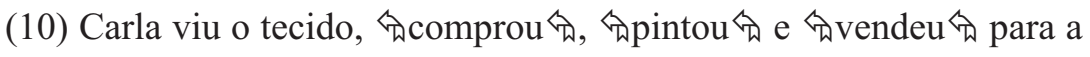


Na medida que se pinta o tecido, aquilo que é pintado já é o tecido acrescido de uma qualificação progressiva, pois se trata do tecido já comprado. Essa progressão se potencializa quando se afirma sobre a venda, pois se trata do tecido pintado, e não mais do tecido que foi visto por Carla. Efetivamente, a força de progressão já atua aqui, e ela se apresenta plena em 12. A nossa hipótese é a de que a força de progressão não atua no lugar do sujeito. Por sua vez, a força de prospecção não atuaria no lugar do objeto.

No texto a seguir, a força de retrospecção é marcante na manutenção da referência, e a força de progressão é decisiva para o desenvolvimento temático.

\section{COMO SE CONJUGA UM EMPRESÁRIO}

Acordou. Levantou-se. Aprontou-se. Lavou-se. Barbeou-se. Enxugou-se. Perfumou-se. Lanchou. Escovou. Abraçou. Beijou. Saiu. Entrou. Cumprimentou. Orientou. Controlou. Advertiu. Chegou. Desceu. Subiu. Entrou. Cumprimentou. Assentou-se. Preparou-se. Examinou. Leu. Convocou. Leu. Comentou. Interrompeu. Leu. Despachou. Conferiu. Vendeu. Vendeu. Ganhou. Ganhou. Ganhou. Lucrou. Lucrou. Lucrou. Lesou. Explorou. Escondeu. Burlou. Safou-se. Comprou. Vendeu. Assinou. Sacou. Depositou. Depositou. Depositou. Associou-se. Vendeu-se. Entregou. Sacou. Depositou. Despachou. Repreendeu. Suspendeu. Demitiu. Negou. Explorou. Desconfiou. Vigiou. Ordenou. Telefonou. Despachou. Esperou. Chegou. Vendeu. Lucrou. Lesou. Demitiu. Convocou. Elogiou. Bolinou. Estimulou. Beijou. Convidou. Saiu. Chegou. Despiu-se. Abraçou. Deitou-se. Mexeu. Gemeu. Fungou. Babou. Antecipou. Frustrou. Virou-se. Relaxou-se. Envergonhou-se. Presenteou. Saiu. Despiu-se. Dirigiu-se. Chegou. Beijou. Negou. Lamentou. Justificou-se. Dormiu. Roncou. Sonhou. Sobressaltou-se. Acordou. Preocupouse. Temeu. Suou. Ansiou. Tentou. Despertou. Insistiu. Irritou-se. Temeu. Levantou. Apanhou. Rasgou. Engoliu. Bebeu. Rasgou. Engoliu. Bebeu. Dormiu. Dormiu. Dormiu. Acordou. Levantou-se. Aprontou-se...

Fonte: Mino. Disponível em: www.pead.letras.ufrj.br/tema09/conceitodecoesao.html. Acessado em 7 jun. 2004.

Observemos que, em todas as sentenças, o lugar do sujeito é afetado pela força de retrospecção, remetendo-nos à fonte de identificação, no plano de anterioridade, constituído no título do texto. Já a força de progressão atua nos verbos das sentenças propiciando o espaço de construção temática no lugar do objeto, que não sofre a injunção à identificação: para "leu", por exemplo, podemos ter "o relatório", "as páginas de economia de um jornal", o "e-mail", etc. A circuns- 
crição dos referentes virtuais nesse lugar sintático é determinado pelo extrato da memória em que a vida empresarial adquire identidade.

Assim, do ponto de vista de uma teoria da enunciação, a materialidade linguística prescinde da presença de unidades lexicais, justamente porque ela é qualificada no plano enunciativo. O lugar sintático nesse processo de qualificação é um lugar de contato entre uma memória de ditos e a atualidade do dizer. Vimos que, enquanto unidades formais, os lugares sintáticos de sujeito e de objeto se qualificam na medida que funcionam como portos de passagem na rota de circulação de sentidos, de discursos para o enunciado, e deste para os espaços futuros da discursividade, que, por sua vez, serão bases para novos enunciados. É nesse sentido que as categorias de sentença e enunciado se encontram na análise enunciativa: base de materialidade, pelo lado da sentença, constituindo-se em materialidade qualificada, pelo lado do enunciado.

\section{Considerações finais}

A abordagem da enunciação, da maneira como a desenvolvemos, traz de Benveniste a tese básica segundo a qual o estudo do emprego das formas não pode prescindir do estudo do emprego da língua. Na medida que buscamos o lugar sintático como forma material qualificada pela relação entre enunciado e sentença, acreditamos estar no caminho daquilo que Benveniste vislumbrou como fundamento de uma teoria da enunciação. Por sua vez, a nossa abordagem traz de Ducrot a própria concepção de acontecimento, na passagem de uma instância do já-enunciado para uma instância de projeção de futuro para outras enunciações, como um dos fundamentos da relação entre o dito e o dizer. Por fim, nos apoiamos em conceitos como enunciável e traços de memória, inspirado nas teses da teoria do discurso de linha francesa sobre a discursividade e o caráter histórico-social do dizer. 


\section{Notas}

1 "Tout cela fait voir que les mots forment les frases; mais qu'ils ne les forment qu'autant qu'ils en énoncent quelque membre ou qu'ils contribuent à l'énoncer" (GIRARD, 1747, p. 123).

${ }^{2}$ Grupo de Pesquisa registrado no CNPQ, liderado por Eduardo Guimarães, com participação de diversos pesquisadores de universidades brasileiras.

${ }^{3}$ Utilizamos o termo "pertinente", para se referir a uma relação de pertença às situações de interação social, isto é, para se referir a algo concernente às relações sociais, e não a algo apropriado à finalidade a que se destina (sentido valorativo). Alguém pode dizer algo pouco ou nada apropriado em determinado contexto de diálogo, mas essa fala teve uma repercussão no diálogo, mesmo que mínima, a ponto de ser captada pelos participantes e concebida como inapropriada ou impertinente.

${ }^{4} \mathrm{O}$ conceito de legível não é valorativo. Portanto, não envolve clareza ou nitidez. Tratase daquilo que é captável pelos sentidos (audição e/ou visão) como pertinente, de acordo com o conceito de pertinência acima.

${ }^{5}$ Em francês, site syntaxique. Traduzimos site por "lugar", no sentido de "lugar qualificado", mas ressaltamos que Milner utiliza o termo place, também traduzível por "lugar", para se referir à localização dos termos na sentença.

${ }^{6}$ Grosso modo, lugar sintático corresponde à posição sintática, ou à função sintática, a depender da perspectiva de sintaxe adotada.

${ }^{7}$ Em Dias (2006), denominamos esse campo de observação de "colmeia".

\section{Referências}

BARBISAN, L. B. O sentido no discurso: o olhar da Teoria da Argumentação na Língua. In: DI FANTI, M. da G.; BARBISAN, L. B. (Org.). Enunciação e discurso: trama de sentidos. São Paulo: Contexto, 2012. p. 133-151.

BENVENISTE, E. [1970] O aparelho formal da enunciação. In: . Problemas de Linguística Geral - 1. Campinas: Pontes, 1989. p. 81-90.

BERRENDONNER, A. Pour une macro-syntaxe. Travaux de linguistique, n. 21, p. 2536, 1990.

BERRENDONNER, A. Morpho-syntaxe, pragma-syntaxe, et ambivalences sémantiques. In: ANDERSEN, H. L.; NOLKE, H. Macro-syntaxe et macro-sémantique. Berne, Peter Lang, 2002. p. 23-41.

BRAIT, B. (Org.) Estudos enunciativos no Brasil: histórias e perspectivas. Campinas: Pontes, 2001.

CAREL, M.; DUCROT, O. La semántica argumentativa. Buenos Aires, Ediciones Colihue, 2005 . 
DELESALLE, S. Histoire du mot énonciation. Histoire Épistémologie Langage, Paris, v. 8, n. 2, p. 7-22, 1986.

DIAS, L. F. Os sentidos do idioma nacional; as bases enunciativas do nacionalismo linguístico no Brasil. Campinas: Pontes, 1996.

DIAS, L. F. Fundamentos do sujeito gramatical: uma perspectiva da enunciação. In: ZANDWAIS, A. (Org.). Relações entre pragmática e enunciação. Porto Alegre: UFGS/Sagra Luzzatto, 2002. p. 47-63.

DIAS, L. F. Novas perspectivas no ensino de gramática na escola: o estatuto do exemplo em questão. In: OLIVEIRA, S. E. de; SANTOS, J. F. (Org.). Mosaico de linguagens. Campinas: Pontes/CELLIP, p.43-53, 2006.

DIAS, L. F. Enunciação e regularidade sintática. Cadernos de Estudos Linguísticos (UNICAMP), Campinas, v.51, p. 7-30, 2009.

DIAS, L. F. Memória, enunciação e lugares sintáticos. In: LEFFA, V. J.; ERNST, A. (Org.). Linguagens; metodologias de ensino e pesquisa. Pelotas: EDUCAT, 2012. p. 27-42.

DUCROT, O. Argumentação retórica e argumentação linguística. Letras de Hoje, Porto Alegre, v. 44, n. 1, p. 20-25, 2009.

FIORIN, J. L. As astúcias da enunciação. São Paulo: Ática, 1996.

FLORES, V. N. Lingüistica e Psicanálise: princípios de uma semântica da enunciação. Porto Alegre: EDIPUCRS, 1999.

FLORES, V. N. Notas para uma (re)leitura da teoria enunciativa de Émile Benveniste. In: TEIXEIRA, M.; FLORES, V. N. (Org.). O sentido na linguagem: uma homenagem à Professora Leci Barbisan. Porto Alegre: EDIPUCRS, p. 153-170, 2012.

FLORES, V. N.; SILVA, S.; LICHTENBERG, S.; WEIGERT, T. Enunciação e Gramática. São Paulo: Contexto, 2008.

GIRARD, G. Les vrais principes de la langue française. Paris, 1747. (Edição facsimilar) GUIMARÃES, E. Texto e argumentação; um estudo de conjunções do português. Campinas: Pontes, 1987.

GUIMARÃES, E. Semântica do acontecimento. Campinas: Pontes, 2002.

GUIMARÃES, E. Domínio semântico de determinação. In: GUIMARÃES, E. J.; MOLLICA, M. C. (Org.). A palavra: forma e sentido. Campinas: Pontes / RG Editores, 2007.

MILNER, J-C. La théorie des positions. In: Introduction à une science du langage. Paris: Éditions du Seuil, p. 357-408, 1989.

TEIXEIRA, A. H. C. Midiáticos e coexistentes: mídia, mito e mediações. 109 p. Dissertação de Mestrado. Bauru, UNESP, 2005. 